\title{
An Extended Survey of Time-Inconsistency and Its Applications
}

\author{
Murat Yılmaz* \\ Boğaziçi University
}

\begin{abstract}
In this study, we provide an extended literature review on preferences with present bias, more specifically with quasi-hyperbolic discounting which leads to time-inconsistent behavior. We review current studies that focus on the implications of time-inconsistent preferences on various well-known economic models and environments, including both models of individual decision making and models that have strategic interactions. We also discuss the part of the literature that focuses on measuring the discounting, whether it is exponential or hyperbolic. We also provide possible research directions which have not been fully explored yet in the literature.
\end{abstract}

Keywords: present bias, time-inconsistency, $\beta \delta$-preferences, sophisticated agent, naive agent, measuring discount factor, commitment.

JEL Classifications: D03, D82, D86.

\section{Zamansal Tutarsızlık ve Uygulamaları Üzerine Geniş Bir İnceleme}

\section{Özet}

$\mathrm{Bu}$ çalışmada, mevcut kazançlara daha fazla önem atayan tercihlere dair geniş bir literatür taraması yapıyor ve özellikle zamansal tutarsızlık yaratan yarı-hiperbolik iskonto fonksiyonu üzerine yoğunlaşıyoruz. Zamansal tutarsızlık içeren tercihler ve bu tercihlerin bir takım ekonomik modellerdeki sonuçlarına odaklanan güncel çalışmaları tartışıyoruz. Hem bireysel karar vericilere dair modellere, hem de stratejik etkileşimin mevcut olduğu modellere odaklanıyoruz. Literatürde eksponensiyel veya hiperbolik olan zamansal tercihleri ölçme üzerine yapılmış çalışmaları inceliyoruz. Ayrıca, henüz tam olarak araştırılmamış bir takım açık araştırma sorularını da tartışıyoruz.

Anahtar Kelimeler: zamansal tutarsızlık, $\beta \delta$-tercihleri, sofistike ajan, naif ajan, iskonto faktörünün ölçümü, taahhüt.

JEL Sinıflandırmasi: D03, D82, D86.

* Murat Yılmaz is an Assistant Professor in the Department of Economics at Boğaziçi University, Natuk Birkan Building, 34342, Bebek, Istanbul, Turkey. Email: muraty@boun.edu.tr 
7 here are a growing number of studies that present evidence showing that agents' behavior often exhibit time-inconsistency. An agent today may plan to take an action tomorrow, but when tomorrow arrives the agent changes her mind and takes another action. This change in choice behavior is usually referred to as timeinconsistency. One may see it as different selves of the same agent having disagreements on future actions or choices. When all the different selves agree, then the agent is said to be time-consistent. If, however, at least some selves disagree on future choices, then the agent is time-inconsistent.

When the benefits of an action are in the future and the costs are immediate, agents do not give the benefits much weight. That is, they tend to postpone costly actions and tough projects (e.g. finishing up writing a paper, filing taxes or going to the gym), but rarely tend to postpone gratification. This behavior is usually attributed to a possible present-bias an agent may have, and it is captured or implied by quasi-hyperbolic discounting scheme, or through $\beta \delta$-preferences. There is already a substantial amount of work regarding individual decision making under $\beta \delta$-preferences and time-inconsistency, and a growing number of studies that focus on economic interactions and strategic environments that include time-inconsistent individuals.

Frederick, Loewenstein, and O'Donoghue (2002) provide an overview of the literature and Loewenstein and Prelec (1992) lay out a survey on anomalies in intertemporal choice. However, these studies are by now relatively old and there has been a large amount of work done in the field since these two surveys. The goal of this study is to provide a more comprehensive and also a more up-to-date survey of the relevant literature. We aim to lay out an extensive review of the literature and present the growing importance of time-inconsistent preferences and their implications for important economic problems. Our goal is to provide a detailed analysis of different lines of research in this literature, including individual decision making problems, economic problems involving strategic interaction and also measurement of time-preferences. We will discuss some of the pioneering papers as well as the frontier research and we also hope to shed light on possible research directions one could pursue in this field.

In Section 2, we provide an extensive survey of the current literature on the subject. Section 3 provides possible directions in the field, which have not been explored yet. Section 4 concludes.

\section{What We Know so Far}

In 1937, Samuelson introduced the Discounted Utility model, DU, henceforth, and since then it has been heavily used in almost all dynamic models of intertemporal choice. The model introduced by Samuelson (1937) says that an individual prefers a stream of consumption levels $\mathrm{c}=\left(\mathrm{c}_{0}, \mathrm{c}_{1}, \ldots, \mathrm{c}_{\mathrm{T}-1}, \mathrm{c}_{\mathrm{T}}\right)$ over another one $\mathrm{c}^{\prime}=\left(\mathrm{c}_{0}^{\prime}, \mathrm{c}_{1}^{\prime}, \ldots, \mathrm{c}_{\mathrm{T}-1}^{\prime}, \mathrm{c}_{\mathrm{T}}^{\prime}\right)$ if and only if 


$$
\sum_{t=0}^{T} \delta^{t} u\left(c_{t}\right) \geq \sum_{t=0}^{T} \delta^{t} u\left(c^{\prime}{ }_{t}\right)
$$

where $\mathrm{u}(\cdot)$ represents the individual's utility function over consumption levels and $\delta \in[0,1]$ represents the discount factor for one period. However, there have been a number of anomalies reported regarding intertemporal choice. Loewenstein and Prelec (1992) discuss four common preference anomalies that do not go along with the DU model. The first anomaly is the common difference effect. An example given by Thaler (1981) explains this anomaly very clearly: an individual might prefer one apple today to two apples tomorrow, but at the same time prefer two apples in 51 days to one apple in 50 days. The second one is the absolute magnitude effect, where larger amounts are discounted less than the smaller amounts. As reported by Thaler (1981), on average subjects were indifferent between $\$ 15$ and $\$ 60$, indifferent between $\$ 250$ and $\$ 350$, as well as between $\$ 3000$ and $\$ 4000$. The third anomaly is the gain-loss asymmetry. According to Loewenstein (1987) subjects were, on average, indifferent between getting \$10 immediately and getting \$21 in one year, and indifferent between losing \$10 immediately and losing $\$ 15$ in one year. Finally, the last one is the delay-speed up asymmetry. This effect involves an asymmetric preference between speeding up and delaying consumption. The finding reported by Loewenstein (1988) is that on average, the amount an individual asks in order to delay a given reward, say by t periods, is two to four times larger than the amount this individual is willing to give up in order to receive the reward $t$ periods earlier.

Working on these anomalies, Loewenstein and Prelec (1992) mainly find that individuals are less sensitive to the changes in the timing of substantially delayed rewards, relative to the changes that are not delayed that much. As we pointed out via Thaler's (1981) finding, $\$ 100$ may be better than $\$ 110$ tomorrow, but at the same time, $\$ 110$ that will be received 51 days later may be better than $\$ 100$ that will be received in 50 days. This finding is parallel with the idea of time-inconsistent preferences. Also, Kirby and Herrnstein (1995) conduct an experimental study that challenges the stationarity axiom and finds evidence for preference reversals, which is predicted by hyperbolic discounting models. ${ }^{[1]}$

Frederick, Loewenstein, and O'Donoghue (2002) also provide a critical view on time-preferences and the DU model introduced by Samuelson (1937), which we discussed above. They point out that empirically discount rates are not constant over time, unlike in the DU model. They also provide an extensive list of empirical or experimental studies that measure discount rates. We will discuss some of these studies in the section on Measuring Discount Factors.

When modelling time-inconsistency, most of the current literature uses the $\beta \delta$ discounting model, in which the discount factor is not constant over time. Before re-

[1] Also see Rubinstein (2003), where he documents that the experimental evidence that rejects exponential discounting can also be utilized to reject hyperbolic discounting. 
viewing the current literature, we first provide this model of time-inconsistency. There are other models and approaches that also capture time-inconsistent behavior. ${ }^{[2]}$ We will review these below as well.

\section{$\boldsymbol{\beta} \boldsymbol{\delta}$-discounting}

When an agent has $\beta \delta$-discounting, then her present value of a flow of future utilities as of period t will be given by

$$
v_{t}+\beta \sum_{s=t+1} \delta^{s-t} v_{s}
$$

where $\mathrm{v}_{\mathrm{t}}$ denotes her period $\mathrm{t}$ utility. With this formulation, note that the discount factor between the current period and the next period is $\beta \delta$, but the discount factor between two adjacent periods in the future is $\delta$. The agent is time-consistent (exponential discounter) when $\beta=1$, and time-inconsistent (quasi-hyperbolic discounter) when $\beta<1$. A time-inconsistent agent can be fully aware, partially aware or fully unaware of his time inconsistency, that is, of his true $\beta$. Suppose the agent believes that his true $\beta$ is $\hat{\beta}$. As in the literature, a time-inconsistent agent is sophisticated when he is fully aware of his inconsistency, that is, when $\hat{\beta}=\beta<1$. The agent is partially naive when $\beta<\hat{\beta}<1$ and fully naive when $\beta<\hat{\beta}=1$. The agent is naive when $\beta<\hat{\beta} \leq 1$. ${ }^{[3]}$

Hyperbolic discount functions are very much related to time-inconsistency described above. When an individual uses a hyperbolic discount function, she has a relatively high discount rate over short horizons and relatively low discount rate over long horizons. This induces a conflict between today's self and tomorrow's self. From today's perspective the discount rate between two consecutive periods in the far future may be small, through a large discount factor, like $\delta$. However, the discounting between two consecutive periods in the near future may be large, through a small discount factor, like $\beta \delta$. Thus, hyperbolic discounting induces the $\beta \delta$-preferences we described above. This is parallel to the example Thaler (1981) gave, which we discussed above. According to Laibson (1997), another example is the following: "this year I may desire to start an aggressive savings plan next year, but when next year actually rolls around, my taste at that time will be to postpone any sacrifices another year." Here, through a very simple example, we show why this type of $\beta \delta$-discounting may lead to time-inconsistency. ${ }^{[4]}$ Suppose an agent has to make an investment decision today at $t=1$, where the investment costs 6 units at date $t=2$ and a benefit of 8 units is collected with a delay at date $t=3$. Suppose the agent has $\beta \delta$-discounting with $\beta=1 / 2$ and $\delta=1$. From $t=1$ point of view, the agent calculates the overall net payoff from the investment: $0+\beta \delta \cdot(-6)+\beta \delta^{2} \cdot 8=-3+4=1>0$. Thus, at $\mathrm{t}=1$, the agent decides to undertake the investment project at $\mathrm{t}=2$. However,

\footnotetext{
[2] See Eliaz and Spiegler (2006), for instance.

[3] There is also some limited empirical and experimental evidence showing that there may be future bias, which, in this context, translates into the time inconsistency parameter $\beta$ being larger than 1. See Sayman and Öncüler (2009); Takeuchi (2011), for instance.

${ }^{[4]}$ See Chabris, Laibson, and Schuldt (2010) for the details of this example.
} 
when $\mathrm{t}=2$ arrives, the agent recalculates the net payoff from the investment: $-6+\beta \delta$ $\cdot 8=-6+4=-2<0$. Thus, the agent changes her mind and at $t=2$, and she decides not to undertake the investment. Therefore, self at $\mathrm{t}=1$ and self at $\mathrm{t}=2$ have conflicting choices, thus this agent's choice behavior exhibits time-inconsistency. Note that if $\beta=$ 1 , then the investment decision would not change across time.

Among the earliest papers that deal with time-inconsistent preferences, we have Strotz (1955); Phelps and Pollak (1968); Goldman (1979). In 1955, Strotz studied the following question: When an individual is choosing a stream of consumption levels for a number of future periods, if she is free to reconsider her plans at later periods, will she carry out the original plan or change it? Strotz finds that the optimal stream of consumption for future periods that is chosen at the moment will not be obeyed, that is, the individual's future consumption levels will be inconsistent with the optimal plan chosen at the moment. About a decade and a half later, Phelps and Pollak (1968) first formulated the concept of time-inconsistency, introducing a quasi-hyperbolic discounting scheme via $\beta \delta$-discounting in a national savings context. Using the $\beta \delta$-discounting described above, they show that the first best is achieved if the current generations can commit future generations to save the amount that the current generations wish them to save. However, if commitment is not possible, then the optimal saving decision becomes only the second best. Goldman (1979) studied the problem of choice under intertemporally inconsistent preferences, that is, how an individual today should behave knowing that herself tomorrow may not abide with her current decision? Goldman showed that when an equilibrium (subgame perfect Nash equilibrium) exists with an allocation different from the first generation's best plan, then there also exists another plan of consumption which is Pareto superior to the one in the equilibrium. ${ }^{[5]}$

\section{Individual Decision Making}

There is a line of research that considers individuals and their decision making problems under present bias, where individuals do not interact with other individuals. Thus, there is no strategic interaction. ${ }^{[6]}$

One of the most influential papers on decision making with time-inconsistent preferences is Laibson (1997). Laibson studies the implications of hyperbolic discount functions, which induces time-inconsistent preferences. He considers the case where an imperfect commitment device exists. An example is an illiquid asset, the sales revenue of which is obtained with a lag after the sale is initiated. He shows that consumption levels are parallel with income levels and explains why consumers have a different propensity to consume out of wealth than they do out of labor income. He also argues that since financial innovation increases liquidity and eliminates commitment devices,

\footnotetext{
${ }^{[5]}$ In this survey, we focus and discuss those studies that use discrete time models; however, there are a number of studies that work time-inconsistency in continuous time. See, for instance, Karp (2007), Harris and Laibson (2013), and Pan, Webb, and Zank (2015).

${ }^{[6]}$ However, there are some papers, which model individual decision making process as a strategic game between different selves of the same agent.
} 
financial innovation may be responsible for declining savings rates in U.S. In another paper, Laibson (1998) studies hyperbolic discounting and its implications regarding certain anomalies. He shows that it is possible to explain some of the empirical anomalies including declining national savings rates in developed countries, disproportionate retirement accumulation in illiquid assets, consumption discontinuities at retirement, variation in patience and precautionary savings effects. Diamond and Köszegi (2003) introduce endogenous retirement decision into the model of Laibson (1997). They show that the current self may save less in order to make the future self decide on a later retirement, since the current self believes that the future self will retire too soon.

In a series of papers, O'Donoghue and Rabin study the implications of time-inconsistent preferences in some number contexts. In their seminal paper, O'Donoghue and Rabin (1999a) study self-control problems of individuals who have present-biased preferences, which are modelled by time-inconsistent discounting. An individual's problem is when to do an action, which must be done exactly once. The action either has an immediate cost or immediate reward. Also, the individual may be aware of her time-inconsistency (sophisticated) or may be unaware (naive). They show that naive time-inconsistent individuals postpone costly action, they procrastinate, and take actions with immediate rewards too soon. Sophisticated individuals procrastinate less than naive agents but choose to do actions with immediate rewards much earlier than naive agents. The reason for this is that sophisticated individual has realistic pessimism, which makes her take the action earlier than the naive one. Also, when an action has immediate costs, a small present bias harms only naive agents, however with actions with immediate rewards, it harms only sophisticated agents. The intuition is that for the actions with immediate costs (rewards), the future misbehavior raises (lowers) the cost of current misbehavior, and then sophistication helps (hurts) in overcoming short-run impatience.

In another paper, O'Donoghue and Rabin (2000) also study self-control problems under time-inconsistent preferences, and they point out how the timing of the rewards and costs of an action are important, as well as whether an individual is aware of her future self-control problems. Based on the intuition we gave above, they show that sophistication may hurt the agent, when actions have immediate rewards. Furthermore, O'Donoghue and Rabin (2001) study a model where an individual picks from a menu of actions and is partially naive, that is, she is partially aware of her time-inconsistency problem. They find that a partially naive person may find it optimal to not complete an attractive option because she prefers a more attractive action even it's not going to be completed. It is possible to induce a person, who would not procrastinate, to procrastinate by providing a larger set of options. The reason for this is that when we provide a person with a more important new action (with higher return, but also with higher cost), this may cause the agent to switch from doing something useful (the old action that is doable) to doing nothing at all because the new action is harder, thus more open to procrastination. Thus, a person may procrastinate more severely when pursuing more important goals than less important ones. O'Donoghue and Rabin also summarize what we have learned so far in their paper O'Donoghue and Rabin (2015), in which they point out that present bias is about utility, that short-term discounting can be evidence 
for present bias, and that the welfare analysis can be done. They also ask questions for further research and new directions, which we will discuss in Section 3.

In an empirical work, Angeletos, Laibson, Repetto, Tobacman, and Weinberg (2001) study a model of consumption where future labor income is uncertain and consumers have limited ability to borrow since they face liquidity constraints. Also, consumers are assumed to have a short-run preference for instantaneous gratification (immediate gain), as well as a long-run preference to act patiently. They show that hyperbolic discount function performs better in approximating the data relative to exponential discount function, and also that hyperbolic discounting explains consumption declines when retirement approaches. They also explain relatively low levels of liquid wealth and aggressive credit card borrowings. When changes in income are more predictable, consumers are less able to smooth their consumption paths, which reflects the welldocumented empirical fact that consumption and income move together.

Gruber and Köszegi (2001) focus on addictive behavior and provide a new model of addiction, which differs from the standard rational addiction model through the time-inconsistent preferences they incorporate. In an earlier study, Becker and Murphy (1988) show that addiction behavior is consistent with rationality. However, they assume that consumers perfectly predict the current price and future cost of the goods they are addicted to. Gruber and Köszegi, however, avoid this assumption. They track down the consumption levels before and after a change in the tax rate is announced, but not effective yet. Although they get similar results to those in Becker and Murphy (1988) in terms of the effect of future prices, they also show that when hyperbolic discounting is introduced, the implications regarding government policy are quite different. They find that the optimal government policy depends on both the negative externalities of smokers and the internalities imposed by smokers on themselves. Gruber and Köszegi have another study, Gruber and Köszegi (2004), where the taxes levied on cigarettes impose some self-control problems, since smokers would like to quit to avoid the tax but just cannot. They show that time-inconsistent preferences explain the evidence on smoking levels much better than time-consistent preferences. They also explain why poor people smoke more. One intuition is that when an agent is more time-inconsistent then her each self may ignore more of the future harm she causes by smoking more. Thus, a decrease in consumption today would be costlier, and the current self sticks to a high level of smoking.

In their study, Harris and Laibson (2001) focus on a consumer's decision problem where she has hyperbolic discounting function, a borrowing constraint and stochastic income. Using a Hyperbolic Euler Equation, instead of an Exponential Euler Equation, they explain why young and middle-aged consumers borrow through too much credit card transactions, as well as the high level of observed preretirement wealth accumulation.

On a related issue, Meier and Sprenger (2010) study credit card borrowing and test whether time-inconsistent agents borrow too much through credit cards or not. They show that, through incentivized choice experiments, present-biased agents are relatively more likely to be borrowing through credit cards and have larger credit card debt, when compared to agents who are time-consistent. 
İmrohoroğlu, İmrohoroğlu, and Joines (2003) study an economy with time-inconsistent individuals and focus on the social security and its welfare effects on these timeinconsistent agents through an overlapping generations model. Agents face income risk and mortality risk, and they have borrowing constraints. They choose how much to work and how much to save for retirement. What they find in this framework is that social security is beneficial for those agents who find themselves with low consumption levels once retired and regret their earlier saving decisions. But, they also conclude that social security may adversely affect labor supply and overall savings amount in the economy, which in turn affects the interest rate and the wage rate.

In another paper that also focuses on consumption and savings decisions of individuals, Krusell and Smith Jr (2003) introduce time-inconsistent time preferences through $\beta \delta$-discounting into a simple problem of consumption-savings where agents face no uncertainty. Agents are infinitely lived and they need to allocate their resources today into today's consumption and savings, where today's savings will be available for consumption tomorrow, through a given technology for savings. They model this problem as a current self and her infinitely many future selves deciding on consumption and savings. They show an indeterminacy result where there is a continuum of Markov equilibrium savings rule. There is a continuum of stationary points and for each stationary point there is a continuum of consumption-savings path that converges to it. All these continuum of savings rules are in the form of step functions. The intuition behind this step function is as follows. If self $\mathrm{n}$ saves slightly more, this deviation increases the consumption of self $\mathrm{n}+1$ by the amount of the increase and its return, but the future capital stocks remain the same. Thus, under such a deviation, self $\mathrm{n}$ lowers her consumption, increases self $\mathrm{n}+1$ 's consumption, and leaves the consumption of all subsequent selves unchanged. Under a mild condition, this extra saving gives rise to less than the extra income generated next period. Thus, this is not a profitable deviation.

Dasgupta and Maskin (2005) ask whether there is a particular reason for having hyperbolic dis- counting, or $\beta \delta$-preferences. They show that if there is some uncertainty regarding the timing of the payoffs to be realized, then the time preferences have present bias or hyperbolic discounting. The intuition is as follows. Imagine that a decision maker is offered today a small payoff $\mathrm{x}$ at a date $\mathrm{t}$ or a larger payoff $\mathrm{X}>\mathrm{x}$ at a later date $\mathrm{T}>\mathrm{t}$. Also suppose that for each payoff amount, with a small positive probability the payoff will be realized before the promised date. Let's say the decision maker first chooses $(\mathrm{X}, \mathrm{T})$. As time passes and the payoff $\mathrm{X}$ is not realized earlier, then the small but early option $(x, t)$ becomes increasingly attractive. Thus, the decision maker may switch to the smaller and earlier option $\mathrm{x}$.

In a dual-self model, Fudenberg and Levine (2006) assume that there are two kinds of selves, where one is a patient long-run self and the other is a myopic short-run self. These two selves have different preferences about the future payoffs, where the short run selves are myopic. Through this dual-self model, they explain both hyperbolic discounting and the paradox of risk aversion in large and small scales. In the latter, what 
happens is that the agent's risk aversion for small scale gambles implies rejection of favorable large scale gambles. ${ }^{[7]}$

Grenadier and Wang (2007) study the investment decision of a time-inconsistent entrepreneur through a real options model, frequently used in the finance literature. However, most of this literature assumes that agents discount exponentially. Grenadier and Wang introduce time-inconsistency into the real options model and show that investment occurs earlier than in the standard, time-consistent framework.

\section{Strategic Interaction}

In this section, we focus on economic models with strategic interaction under timeinconsistent preferences. The studies we discuss below involve contracting problems and/or dynamic games, including bargaining games, repeated games, principal-agent problems, nonlinear pricing problems and public good provision games.

In O'Donoghue and Rabin (2008), they study a contracting problem through a long term project with multiple stages, when agents are naive and time-inconsistent. They show that when stages have costs that are different enough, then procrastination is more likely, and if the stages are costlier, the project is usually not finished. The intuition is based on the similar reasoning we provided above when discussing their other studies. They also study another incentive problem in O'Donoghue and Rabin (1999b) through a principal-agent model. However, in their model the effort level is observed by the principal, thus no moral hazard problem exists in this sense. Instead, they assume that there is a task which has a cost that can change over time, and they focus on the question of when the agent completes the task. A moral hazard problem may arise though in terms of unobserved (by the principal) task-cost realizations. They show that the second-best optimal contract for naive time-inconsistent agents must have an increasing punishment for delay as time passes. The reason is that higher task costs make the agent more prone to procrastinate, and the principal needs to increase punishments to avoid inefficient procrastination.

Gilpatric (2008) also focuses on a contracting problem with time-inconsistent agents assuming that profit is fully determined by the effort, so effort is effectively observable. However, the low effort level can be severely punished or not, and both cases are considered. In the case where shirking cannot be severely punished (for instance when the worst punishment is to pay the agent nothing), the principal leaves some room for naive time-inconsistent agents to shirk in the second-best solution. This is because if a naive agent thinks that he will not shirk, but then if his future self shirks, such shirking is costlier for this agent. However, when agents are less naive, that is, if $\beta^{\wedge}$ is closer to the actual $\beta$, then the principal may be better off (relative to facing fully naive agents) through screening some of the agents from accepting the contract. When severe punishing is feasible, however, the self-control problem does not disappear, but the principal can exploit the naivete of the agents.

[7] See Rabin (2000) for details. 
Yilmaz (2013) and Yilmaz (2015) also look at a contracting problem between a principal and an agent, where the agent is time-inconsistent and there is a repeated moral hazard problem. The former paper deals with sophisticated agents and the latter one deals with naive agents. These two studies differ from the earlier ones in terms of allowing the standard moral hazard problem where the effort choice of the agent is not observable by the principal, and the usual trade-off between risk and insurance is present. In the optimal wage scheme for a sophisticated time-inconsistent agent in the first paper, the marginal cost of rewarding the agent for high output today exceeds the marginal benefit of delaying these rewards until tomorrow. That is, the principal does not smooth the agent's rewards over time. The principal finds it optimal to reward the good performance more and punish the bad performance more in the early period, relative to the optimal wage scheme for a time-consistent agent. In the second paper, the main finding is that there are no information rents for the principal due to the naivete of the agent, and the principal is indifferent whether facing a naive or a sophisticated agent. Englmaier, Fahn, and Schwarz (2016) also consider long term contractual relationships between a principal and agent. Instead of finitely many periods, they use an infinite horizon relationship, where the principal offers a menu of contracts to time-inconsistent agents that are naive. They show that the effort the principal implements can be inefficiently high when there is limited liability.

Another contracting problem is considered by DellaVigna and Malmendier (2004), where they focus on a contract design problem of a firm which is facing time-inconsistent partially naive agents. They consider goods with immediate costs (investment goods, like gyms) and delayed benefits and goods with immediate benefit and delayed costs (leisure goods, like credit cards). Through studying the design of a set of two part tariffs, they find that an investment good is priced below its marginal cost, whereas a leisure good is priced over its marginal cost. They also document that their theoretical results go in line with the empirical data. ${ }^{[8]}$

An alternative approach to repeated principal-agent relationships involving dynamic inconsistency is provided by Eliaz and Spiegler (2006). The dynamic inconsistency is not captured through $\beta \delta$-discounting, but instead there are two possible utility functions and a naive dynamically inconsistent agent fails to correctly anticipate the true utility function. In that setting, they characterize the optimal menu of contracts when a monopoly is contracting with such dynamically inconsistent agents and show that it includes exploitative contracts for naive agents. The idea is that in the optimal menu of contracts, the principal provides two actions for the naive agent: an imaginary action (the naive agent believes that she will pick this action tomorrow) and a real action (the naive agent ends up picking this action, but does not perceive this in advance). Thus, the principal can use the imaginary action to induce the naive agent to sign exploitative contracts. Heidhues and Köszegi (2009) provide another alternative approach where they

${ }^{[8]}$ Also see DellaVigna and Malmendier (2006) for another paper in which they empirically test whether con- sumers have rational expectations about their future consumption frequency and choose the utility-maximizing contract and in which they find evidence that it is not necessarily the case. 
assume that time-inconsistent agent's two selves, self today and self tomorrow, disagree regarding the consumption level and there is also a costly commitment technology. The agent is exposed to a self-control problem. Self today has beliefs regarding tomorrow's self's preference parameter, which is captured through a continuously distributed density function. They show that more sophisticated agents end up with smaller welfare. ${ }^{[9]}$ The intuition is as follows. When an agent is sophisticated, that is, when she has a better understanding of her future taste, she may take more aggressive attempts to control her self-control problem. However, such aggressive attempts are still inefficient, which decreases her welfare.

Kocherlakota (1996) studies a dynamic decision making problem, where an infinitely lived agent chooses an element from a choice set, in every period of her life. Although this is a decision making problem, it is modelled as an extensive form game, where at every decision node the agent makes a choice, and the game is essentially played with different selves of the same agent, since the agent has time-inconsistent preferences. He introduces a refinement of the subgame perfect Nash equilibrium, and calls it reconsideration-proofness. He shows that the agent receives the same overall payoff at all reconsideration-proof equilibrium paths, whereas there are multiple subgame perfect Nash equilibria with different overall utility levels. In another study, Sarafidis (2006) studies a general framework regarding non-cooperative games and introduces time-inconsistency. Focusing first on finite extensive form games of perfect information, he introduces two solution concepts, which overlap with the subgame perfect Nash equilibrium if the players are sophisticated. However, when some players are naive, then these solution concepts produce different predictions than the subgame perfect Nash equilibrium produces. Two applications are provided: the alternating-offers bargaining game and the durable good monopoly. Infinite horizon games and imperfect information games are also analyzed. Chade, Prokopovych, and Smith (2008) study infinitely repeated games where players have $\beta \delta$-preferences. They characterize the equilibrium payoffs and show that the equilibrium payoff set is not monotonic in $\beta$ or $\delta$.

In terms of collective action problems, Bisin, Lizzeri, and Yariv (2015) show that collective action may cause individual self-control problems to increase leading to excessive government debt. When there is heterogeneity in time preferences of individuals, Jackson and Yariv (2015) show that every Pareto efficient and non-dictatorial method of aggregating utility functions must be time inconsistent.

Among studies that focus on bargaining games where time-inconsistency is present, a recent paper, Schweighofer-Kodritsch (2017), focuses on the seminal study of Rubinstein (1982), and provides a general time-preference framework. In Rubinstein (1982), discounting is assumed to be exponential and the levels of impatience of players determines the allocation players agree on, which is both immediate and efficient. In Schweighofer-Kodritsch (2017), however, players are allowed to have timeinconsistent preferences, thus exponential discounting is not necessarily valid. Under

[9] See also Heidhues and Koszegi (2010) for credit contracts and how the naivete of a time-inconsistent agent can be exploited in the context of competitive credit market with present-biased borrowers, who thus have self-control problems. 
time-inconsistency, he derives optimal punishments, fully characterizes the equilibrium outcomes and also shows for which preference profiles the equilibrium is unique. Akin (2007) also studies an alternating-offers bargaining game as in Rubinstein (1982), and introduces time-inconsistency. His focus is on the effects of learning (of the naive timeinconsistent agent) on the equilibrium outcomes. When the proposer is either naive or partially naive, the offer is never accepted by the receiver, regardless of the type of the receiver or whether the naive proposer is learning or not. When a time-consistent agent proposes, though, the game reaches immediate agreement if the receiver is a naive timeinconsistent agent who never learns. And, a naive time-inconsistent agent's share gets larger if her degree of naivete is larger. ${ }^{[10]}$

Altınok and Yilmaz (2018) study a dynamic voluntary public good provision model and assume that the players are time-inconsistent through their $\beta \delta$-preferences. As in Marx and Matthews (2000), the agents have discontinuous preferences over the total contribution with a jump when the project is completed. They compare the equilibrium outcomes of sophisticated time-inconsistent agents to those of the time-consistent agents and show that for any given public good size sophisticated time- inconsistent agents complete the project earlier than time-consistent agents. The idea is that sophisticated agents realize that their future selves may under-contribute, thus they contribute more (relative to time-consistent agents) in the earlier periods, and achieve provision faster.

\section{Measuring Discount Factors}

Since the DU model has been introduced by Samuelson (1937), there also have been a number of studies that are interested in actually soliciting the time preferences. The DU model assumes that a single discount rate measures an agent's time preferences, and a good number of studies had attempted to measure this discount rate, either through experimental data obtained by responses of subjects to a set of choice questions, or through actual choice behavior observed in the real world. Frederick, Loewenstein, and O'donoghue (2002) report a large set of estimates of discount factors presented in the studies up until 2002, together with their method and whether the discounting is found to be exponential or hyperbolic. ${ }^{[11]}$ Unfortunately there is a considerable amount of variation in these estimates and there seems to be no consensus on whether the time-preferences exhibit exponential or hyperbolic discounting. Also, Cohen, Ericson, Laibson, and White (2016) provide an extensive survey of those studies that are primarily interested in measuring or eliciting the time-preferences.

One methodology employed to measure the discounting is referred to as multiple price lists (MPL), where subjects are asked multiple times to choose between smaller payment amounts to be paid at early dates and larger amounts to be paid at later dates. The price lists are such that the interest rate is increasing and at some point the subject starts choosing later payments instead of sooner payments. Using these price levels where this switching occurs, one can estimate the discount rate. The MPL method usually as-

\footnotetext{
${ }^{[10]}$ Also see Akin $(2009,2012)$ for more on bargaining and learning.

${ }^{[11]}$ See Table 1 and Figure 2 in Section 6 of Frederick, Loewenstein, and O'donoghue (2002).
} 
sumes that the utility is linear in monetary payoffs. For instance, Benhabib, Bisin, and Schotter (2010) experimentally estimate discounting using the dated rewards technique. Their estimated discounting function is general in the sense that it nests both exponential and hyperbolic discounting, including quasi-hyperbolic discounting. They find that the discounts rates are high and find strong evidence for present bias. However, the form of present bias does not necessarily result from the quasi-hyperbolic discounting. ${ }^{[12]}$

There is also a branch of this part of the literature that focuses on the risk attitudes when studying time-preferences. If the utility function is not linear, but instead concave, that is, if the agent is risk averse, then the estimates of the discount rate will be upwardbiased. This bias was taken into account by Andersen, Harrison, Lau, and Rutström (2008), where, through an experimental study, they elicit risk and time preferences using Danish adults as subjects, and using a double multiple price list (DMPL) method, where they jointly use time and risk price lists. They find that the discount rates are significantly lower relative to the estimates in earlier studies. They point out that if the subjects are assumed to be risk-neutral, even though they are actually risk-averse, then the discount rates will be overestimated.

Another approach, called Convex Time Budget (CTB) method, on the other hand, captures both discounting and risk attitude at the same time by convexifying the experimental budget. Moreover, this method is able to point estimate the discount rate, unlike MPL which produces a range estimate for it. Andreoni and Sprenger (2012) introduce and use this CTB method, where they use variation in linear budget constraints over early and later payoffs to single out convexity of preferences and produce precise estimates both at the individual level and aggregate level for discount rate and risk-aversion. On average, they find that the discount rates are lower than those estimated in previous studies. Andreoni, Kuhn, and Sprenger (2015) compare these two methods, the CTB method and the DMPL method. They find that it is necessary to control for the risk aversion in order to estimate the discount rate and they also show that the CBT method's estimates out-perform the DMPL's estimates.

Most of the literature studying present-bias either experimentally shows that there is time-inconsistency when monetary payoffs are intertemporally compared or assume that inconsistency arises over monetary payoffs in theoretical models. However, Augenblick, Niederle, and Sprenger (2015) take a different approach in this sense and they focus on real effort choices and show that present-bias exists in real effort costs, but that there is limited time-inconsistency when choices are monetary payments.

Noor (2009b) conducts a calibration exercise where they show that the choice behavior reported in the experiments in Thaler (1981) is also consistent with exponential discounting. The utility of monetary gains is assumed to have constant absolute risk aversion and the marginal utility is assumed to be almost constant. In another paper, Noor (2009a) shows that the magnitude effect and the decreasing impatience properties together contradict the exponential discounting model. When a decision maker

${ }^{[12]}$ Also see Halevy (2015) for an experimental result that points out the present-bias is not necessarily the main source of time-inconsistent behavior. 
has decreasing impatience then it means that she becomes more patient regarding the decision between period $t$ and period $t+1$, as $t$ increases. Magnitude effect is present when a decision maker shows greater patience when the reward is larger.

There is also a number of axiomatic studies regarding the measurement of discounting. Attema, Bleichrodt, Rohde, and Wakker (2010) introduce time-tradeoff sequences to study the intertemporal behavior and manage to resolve the two problems that interfere when measuring the discount factors: the diminishing marginal utility and violation of intertemporal separability. ${ }^{[13]}$ They provide an axiomatic characterization of quasihyperbolic discounting and also experimentally test their axioms. They find evidence for increasing impatience. In a relatively recent study, Olea and Strzalecki (2014) provide an axiomatic characterization for quasi-hyperbolic discounting, the $\beta \delta$-discounting. They also estimate intervals for the discount factors, documenting evidence for both present and future bias. ${ }^{[14]}$

Regarding job search behavior, DellaVigna and Paserman (2005) focus on unemployed subjects. Through their observed job search behavior, the authors find evidence for time-inconsistent time preferences, specifically for $\beta \delta$ discounting. They show that when inconsistency is larger (small $\beta$ ) and discounting low (high $\delta$ ) it takes longer to find a job. They also estimate $\beta$, through calibration of the model, to be around 0.9. In a related study, Paserman (2008) estimates a similar model of job search and unemployment with a quasi-hyperbolic discount function; he estimates $\beta$ and finds that it is approximately 0.5 for low income workers and 0.9 for high income workers. Another empirical study on measuring the degree of time-inconsistency is Fang and Silverman (2009). Through the data on the choices of never-married women with dependent children, they study the relationship between time discounting and work and welfare program participation decisions, and estimate a dynamic structural model of labor supply, and they find evidence for a time-inconsistent discount function. Through a quasi-hyperbolic form, they estimate a present-bias factor considerably less than one, and reject a standard exponential discounting model.

\section{Open Directions}

The literature on present-bias and time-inconsistent behavior has been growing rapidly for the last couple of decades. There have been a large number of important implications stemming from time-inconsistent behavior in various economic contexts. Yet, there are still some directions that are worth pursuing. Some of the economic contexts that have been studied under present bias or time-inconsistency need to be explored more. For instance, the bargaining problems, the public good provision problems and collective decision environments, we believe, are among the fields where there is more to explore when there are time-inconsistencies.

\footnotetext{
${ }^{[13]}$ A time-tradeoff sequence is a sequence $\left(t_{n}, a\right)$ and $\left(t_{n}, b\right)$, for $n=1,2, \ldots$, where $a<b$ and the decision maker is indifferent between $\left(t_{n}, a\right)$ and $\left(t_{n}+1, b\right)$ for all $n=1,2, \ldots$.

${ }^{[14]}$ Also, see Loewenstein and Prelec (1992) and Fishburn and Rubinstein (1982), where the former axiomatized the hyperbolic discounting where the latter axiomatized the exponential discounting.
} 
In most of the studies on time-inconsistency, whether a player is time-inconsistent or not is usually known. However, it is also worth studying incomplete information in this aspect. For instance, in the context of a sequential bargaining, for instance, how does the existence of present bias affect the final outcome in a sequential bargaining game when players have incomplete information on the type of their opponent? When players have missing information on the opponent's type: time-consistent, sophisticated timeinconsistent or naive time-inconsistent, the following questions are relevant and worth pursuing: Controlling for the discounting (for $\delta$ ), what is the effect of time-inconsistency (of $\beta$ ) on the offers made throughout the game and how does the accept-reject decision change? Would the players regret their offers or their accept-reject decisions? What are the implications of awareness of one's own time-inconsistency in this context? For instance, when a naive time-inconsistent agent and a sophisticated time-inconsistent agent bargain sequentially, which agent would have the advantage, controlling for the overall discounting? Under incomplete information, these are open questions that are waiting to be explored in this context. ${ }^{[15]}$

It has been shown by Altınok and Y1lmaz (2018), that in a dynamic public good provision game, time-inconsistent agents contribute more than time-consistent agents, thus there are some efficiency gains in this particular context of public good provision. One direction is whether this result can be generalized to include more economic contexts or not. It would be highly interesting if one could prove a general result that shows the existence of efficiency gains due to time-inconsistency in more general environments.

There are also questions yet to be studied in more detail, as O'Donoghue and Rabin (2015) pointed out. The prediction of discounting behavior seems to be in need of more exploration as there is not a clear consensus on it. Depending on the context or on the assumptions made, the estimates vary by a good margin. It is also important to distinguish present bias with other phenomena like projection bias (where the current decision may be distorted by misprediction of future preferences), anticipatory utility (where there may be additional utility from anticipating future consumption), habit formation (where current utility depends on the past consumption) and demand for commitment (where a sophisticated decision maker may want to acquire a commitment device in order to restrict her future selves with whom she may disagree).

\section{Conclusion}

We surveyed the literature on present bias and quasi-hyperbolic discounting in the form of $\beta \delta$-discounting and their implications in various economic contexts under timeinconsistent behavior, as well as issues with the measurement of discounting functions/ rates. We provided a detailed layout of the different lines of works in the literature and discussed some of the pioneering papers, as well as the frontier research, together with possible future studies.

${ }^{[15]}$ Note that some of these questions are already studied under complete information. 


\section{References}

Akın, Z. (2007). “Time Inconsistency and Learning in Bargaining Games," International Journal of Game Theory, 36(2): 27-299.

------, (2009). "Imperfect Information Processing in Sequential Bargaining Games with Biased Preferences," Journal of Economic Psychology, 30(4): 642-650.

------, (2012): “Intertemporal Decision Making with Present Biased preferences," Journal of Economic Psychology, 33(1): 30-47.

Altınok, A. and Yılmaz, M. (2018). "Dynamic Voluntary Contribution to a Public Project under Timeinconsistency," Journal of Economic Behavior \& Organization, 145: 114-140.

Andersen, S., Harrison, G.W., Lau, M.I., and Rutström, E.E. (2008). "Eliciting Risk and Time Preferences," Econometrica, 76(3): 583-618.

Andreoni, J., Kuhn, M.A., and Sprenger, C. (2015). "Measuring Time Preferences: A Comparison of Experimental Methods,” Journal of Economic Behavior \& Organization, 116: 451-464.

Andreoni, J. and Sprenger, C. (2012). "Estimating Time Preferences from Convex Budgets," The American Economic Review, 102(7): 3333-3356.

Angeletos, G.M., Laibson, D., Repetto, A., Tobacman, J., and Weinberg, S. (2001). "The hHyperbolic Consumption Model: Calibration, Simulation, and Empirical Evaluation," The Journal of Economic Perspectives, 15(3): 47-68.

Attema, A.E., Bleichrodt, H., Rohde, K.I., and Wakker, P.P. (2010). "Time-tradeoff Sequences for Analyzing Discounting and Time Inconsistency,” Management Science, 56(11): 2015-2030.

Augenblick, N., Niederle, M., and Sprenger, C. (2015). "Working over Time: Dynamic Inconsis- tency in Real Effort Tasks," The Quarterly Journal of Economics, 130(3): 1067-1115.

Becker, G.S. and Murphy, K.M. (1988). “A Theory of Rational Addiction,” Journal of political Economy, 96(4): 675-700.

Benhabib, J., Bisin, A., and Schotter, A. (2010). "Present-bias, Quasi-hyperbolic Discounting, and Fixed Costs," Games and Economic Behavior, 69(2): 205-223.

Bisin, A., Lizzeri, A., and Yariv, 1.. (2015). “Government Policy with Time Inconsistent Voters,” The American Economic Review, 105(6): 1711-1737.

Chabris, C.F., Laibson, D.I., and Schuldt, J.P. (2010). "Intertemporal Choice," in Behavioural and Experimental Economics: 168-177. Springer.

Chade, H., Prokopovych, P., and L. Smith, L. (2008). "Repeated games with present-biased preferences," Journal of Economic Theory, 139(1): 157-175.

Cohen, J.D., Ericson, K.M., Laibson, D., and White, J.M. (2016). "Measuring Time Prefer- ences," Discussion paper, National Bureau of Economic Research.

Dasgupta, P. and Maskin, E. (2005). "Uncertainty and Hyperbolic Discounting," The American Economic Review, 95(4): 1290-1299.

DellaVigna, S. and Malmendier, U. (2004). "Contract Design and Self-control: Theory and Evi- dence," The Quarterly Journal of Economics, 119(2): 353-402.

------, (2006). "Paying Not to Go to the Gym,” The American Economic Review, 96(3): 694-719.

DellaVigna, S. and Paserman, M.D. (2005). "Job Search and Impatience," Journal of Labor Economics, 23(3): 527-588. 
Diamond, P., and B. Köszegi, B. (2003). "Quasi-hyperbolic discounting and retirement," Journal of Public Economics, 87(9): 1839-1872.

Eliaz, K. and Spiegler, R. (2006). "Contracting with Diversely Naive Agents," The Review of Economic Studies, 73(3): 689-714.

Englmaier, F., Fahn, M., and Schwarz; M.A. (2016). "Long-Term Employment Relations when Agents are Present Biased," Discussion paper, CESifo Working Paper Series No. 6159.

Fang, H. and Silverman, D. (2009): "Time-inconsistency and Welfare Program Participation: Evidence from the NLSY," International Economic Review, 50(4): 1043-1077.

Fishburn, P.C. and Rubinstein, A. (1982). “Time Preference," International Economic Review, 23(3): 677-694.

Frederick, S., Loewenstein, G., and O'donoghue, T. (2002). "Time Discounting and Time Pref- erence: A Critical Review," Journal of Economic Literature, 40(2): 351-401.

Fudenberg, D. and Levine, D.K. (2006). "A Dual-self Model of Impulse Control," The American Economic Review, 96(5): 1449-1476.

Gilpatric, S.M. (2008). "Present-biased Preferences, Self-awareness and Shirking," Journal of Economic Behavior \& Organization, 67(3): 735-754.

Goldman, S.M. (1979). "Intertemporally Inconsistent Preferences and the Rate of Consumption," Econometrica: Journal of the Econometric Society, 47(3): 621-626.

Grenadier, S.R. and Wang, N. (2007). "Investment under Uncertainty and Time-inconsistent Preferences," Journal of Financial Economics, 84(1): 2-39.

Gruber, J. and Köszegi, B. (2001). "Is Addiction "Rational”? Theory and Evidence," The Quarterly Journal of Economics, 116(4): 1261-1303.

------, (2004). "Tax Incidence when Individuals are Time-inconsistent: The Case of Cigarette Excise Taxes," Journal of Public Economics, 88(9-10): 1959-1987.

Halevy, Y. (2015). "Time Consistency: Stationarity and Time Invariance," Econometrica, 83(1): 335-352.

Harris, C. and Laibson, D. (2001). "Dynamic Choices of Hyperbolic Consumers," Econometrica, 69(4): 935-957.

------, (2013). “Instantaneous Gratification,” The Quarterly Journal of Economics, 128(1:, 205-248.

Heidhues, P. and Köszegi, B. (2009). "Futile Attempts at Self-Control," Journal of the European Economic Association, 7(2-3): 423-434.

------, (2010). "Exploiting Naivete about Self-control in the Credit Market," The American Economic Review, 100(5): 2279-2303.

İmrohoroğlu, A., İmrohoroğlu, S., and Joines, D.H. (2003). "Time-inconsistent Preferences and Social Security," The Quarterly Journal of Economics, 118(2): 745-784.

Jackson, M. and Yariv, 1. (2015). "Collective Dynamic Choice: The Necessity of Time Inconsis- tency," American Economic Journal: Microeconomics, 7(4): 150-78.

Karp, L. (2007). "Non-constant Discounting in Continuous Time," Journal of Economic Theory, 132(1): 557-568.

Kirby, K.N. and Herrnstein, R.J. (1995). "Preference Reversals due to Myopic Discounting of Delayed Reward," Psychological Science, 6(2): 83-89. 
Kocherlakota, N.R. (1996). "Reconsideration-proofness: A Refinement for Infinite Horizon Time Inconsistency," Games and Economic Behavior, 15(1): 33-54.

Krusell, P. Smith Jr, A.A. (2003). "Consumption-savings Decisions with Quasi-geometric Discounting," Econometrica, 71(1): 365-375.

Laibson, D. (1997). “Golden Eggs and Hyperbolic Discounting,” The Quarterly Journal of Economics, 112(2),: 443-477.

------, (1998). "Life-cycle Consumption and Hyperbolic Discount Functions," European Economic Review, 42(3): 861-871.

Loewenstein, G. (1987). The Weighting of Waiting: Response Mode Effects in Intertemporal Choice. Center for Decision Research, Graduate School of Business, University of Chicago.

Loewenstein, G. and Prelec, D. (1992). "Anomalies in Intertemporal Choice: Evidence and an Interpretation," The Quarterly Journal of Economics, 107(2): 573-597.

Loewenstein, G.F. (1988). "Frames of Mind in Intertemporal Choice," Management Science, 34(2): 200-214.

Marx, L.M. and Matthews, S.A. (2000). "Dynamic voluntary contribution to a public project," The Review of Economic Studies, 67(2): 327-358.

Meier, S. and Sprenger, C. (2010). "Present-biased Preferences and Credit card Borrowing," American Economic Journal: Applied Economics, 2(1): 193-210.

Noor, J. (2009a). "Decreasing Impatience and the Magnitude Effect Jointly Contradict Exponential Discounting," Journal of Economic Theory, 144(2): 869-875.

------, (2009b). "Hyperbolic Discounting and the Standard Model: Eliciting Discount Functions," Journal of Economic Theory, 144(5): 2077-2083.

O’Donoghue, T. and Rabin, M. (1999a). "Doing It Now or Later," American Economic Review, 89(1): 103-124.

------, (1999b). “Incentives for Procrastinators,” Quarterly Journal of Economics, 114(3): 769-816.

------, (2000). “The Economics of Immediate Gratification," Journal of Behavioral Decision Making, 13(2): 233.

------, (2001). “Choice and Procrastination,” Quarterly Journal of Economics, 116(1): 121-160.

-----, (2008). "Procrastination on Long-term Projects," Journal of Economic Behavior \& Organization, 66(2): 161-175.

------, (2015). "Present Bias: Lessons Learned and to be Learned," The American Economic Review, 105(5): 273-279.

Olea, J.L.M. and Strzalecki, T. (2014). "Axiomatization and Measurement of Quasi-hyperbolic Discounting," The Quarterly Journal of Economics, 129(3): 1449-1499.

Pan, J., Webb, C.S., and H. Zank, H. (2015). "An Extension of Quasi-hyperbolic Discounting to Continuous Time," Games and Economic Behavior, 89: 43-55.

Paserman, M.D. (2008). "Job Search and Hyperbolic Discounting: Structural Estimation and Policy Evaluation," The Economic Journal, 118(531): 1418-1452.

Phelps, E.S. and Pollak, R.A. (1968). "On Second-best National Saving and Game-equilibrium Growth," The Review of Economic Studies, 35(2): 185-199. 
Rabin, M. (2000). "Risk Aversion and Expected-utility Theory: A cClibration Theorem," Econometrica, 68(5): 1281-1292.

Rubinstein, A. (1982). "Perfect Equilibrium in a Bargaining Model," Econometrica, 50(1): 97-109.

------, (2003). "Economics and Psychology"? The Case of Hyperbolic Discounting, International Economic Review, 44(4): 1207-1216.

Samuelson, P.A. (1937). "A Note on Measurement of Utility," The Review of Economic Studies, 4(2): 155-161.

Sarafidis, Y. (2006). “Games with Tme Inconsistent Players," Discussion paper, Available at SSRN 954394.

Sayman, S. and Öncüler, A. (2009). “An Investigation of Time Inconsistency, ” Management Science, 55(3): 470-482.

Schweighofer-Kodritsch, S. (2017). "Time Preferences and Bargaining,” Discussion paper, HumboldtUniversity Berlin and WZB Berlin Social Science Center.

Strotz, R.H. (1955). "Myopia and Inconsistency in Dynamic Utility Maximization," The Review of Economic Studies, 23(3): 165-180.

Takeuchi, K. (2011). "Non-parametric Test of Time Consistency: Present Bias and Future Bias," Games and Economic Behavior, 71(2): 456-478.

Thaler, R. (1981). “Some Empirical Evidence on Dynamic Inconsistency,” Economics Letters, 8(3): 201-207.

Y1lmaz, M. (2013). "Repeated Moral Hazard with a Time-inconsistent Agent," Journal of Economic Behavior \& Organization, 95: 70-89.

------, (2015). "Contracting with a Naïve Time-inconsistent Agent: To Exploit or Not to Exploit?," Mathematical Social Sciences, 77: 46-51. 